\title{
Tema 5. Desarrollo moral de los niños
}

\section{Presentación}

El tema del desarrollo moral para los educadores y los profesionales de las ciencias humanas suele evadirse debido al temor de acercarse a un supuesto discurso religioso, pero nada más alejado de dicha versión que el estudio acucioso y minucioso sobre el desarrollo moral en el niño de autores como el mismo Piaget, Williams y Kohlberg, quienes dilucidan el proceso moral como una construcción en la cual el niño pasa de una fase heterónoma (seguir la norma de otros) a fases autónomas (saber el sentido de las normas y tomar decisiones propias), y a la formación de su propio criterio o juicio moral.

\section{Propósito (objetivo)}

Reconocer los principales estadios del criterio moral del niño y la niña y su importancia al determinar el comportamiento de este en sus relaciones con los demás y en la construcción de competencias ciudadanas. 


\section{Conceptualización general}

Aquí tomaremos parte de la descripción de los seis estadios del desarrollo moral expuestos por Kohlberg en su obra Conducta y desarrollo moral. Aunque incluye periodos de edad definidos, asumiremos que estos no se aplican de la misma manera a los niños de Colombia, dado que en nuestra realidad las condiciones sociohistóricas en que se da su desarrollo son distintas y difieren de las de los niños estadounidenses y europeos.

\section{Estadio 1. Moralidad heterónoma}

El niño está a merced de los deseos de los otros, obedece por temor al castigo y justifica sus acciones a partir de lo que le han dicho los mayores. Su punto de vista responde al pensamiento egocéntrico, en el sentido en que no tiene aún la capacidad para relacionar puntos de vista diferentes a los que ha tomado por imitación. A la pregunta: ¿por qué dice eso? El niño responde: "Porque mi papá lo dijo".

\section{Estadio 2. Individualismo o egocentrismo}

Las metas del niño son instrumentales, sigue las reglas solo si le conviene, toma la norma en sentido empírico, el bien lo define como aquello que le es útil, a pesar de saber que el otro tiene intereses diferentes, por ejemplo: el niño preferirá estar con el amigo que tenga los juguetes sin considerar si deja a su otro compañero solo.

\section{Estadio 3. Expectativas interpersonales (cooperación)}

El niño empieza a actuar según lo que los demás esperan de él para ganar admiración y aceptación, y asume que el buen comportamiento trae ganancias. Aquí empieza a tener en cuenta los valores y sentimientos de los demás, y aprende a ponerse en el lugar del otro, imaginando qué sentiría en una situación similar a la del otro. Es en esta modalidad de juicio moral en la cual se articulan las primeras competencias ciudadanas asociadas con la cooperación y la solidaridad. 


\section{Estadio 4. Conciencia del bien social}

El menor encuentra que el bien no lo hacen solo las personas sino también las instituciones sociales, por eso asume que su bien está en ir más allá de lo que hace para sí y su familia, con lo cual comprende la idea de poder contribuir con la sociedad. Sin embargo, si la institucionalidad del entorno social es frágil, es muy difícil poder instaurar esta relación y, por ende, la idea es la justicia mediada por terceros.

\section{Estadio 5. Asimilación del contrato social (apropiación de competencias ciudadanas)}

El niño incorpora la concepción del respeto a la diferencia dada por el reconocimiento de la diversidad y pluralidad social de los grupos que conforman el entorno público, por lo cual comprende que el papel de la ley está en situar un medio o referente que le permita a la mayoría contratar socialmente sobre sus derechos y deberes, asimila igualmente la relatividad de las normas y valores, pero dejando un margen para valores esenciales incuestionables: la vida, la libertad y el bien común.

\section{Estadio 6. Principios éticos universales}

Ya en la preadolescencia o adolescencia se comprende que los contratos sociales se apoyan en principios universales, tales como los derechos humanos. Aquí se da especial importancia a la capacidad de lograr acuerdos con el otro y a la solución mediada de conflictos.

Estas son las fases propuestas por Kohlberg, las cuales tienen como base las formuladas por Jean Piaget, entre las cuales se destacan las siguientes:

- Fase egocéntrica: en la cual el niño interpreta el mundo desde sus deseos, es un momento en el que no ha alcanzado a desarrollar el reconocimiento de los intereses del otro. El comportamiento del niño se asemeja a la descripción del "pequeño tirano", aportada por el psicoanálisis, en la que por medio de 
pataletas, rabietas y exigencias busca dominar la autoridad de sus padres.

- Fase heterónoma: o de coacción, ve en las normas algo que viene de afuera, de sus padres o de la escuela, y justifica sus actos imitando las justificaciones de aquellos.

- Fase cooperativa: en ella el niño entra en juegos colectivos, hace negociaciones con sus pares y se siente gratificado al ver que puede servir a los demás. "El niño encuentra en sus hermanos y hermanas, o en sus compañeros de juego, una forma de sociedad que desarrolla su deseo de cooperación. Esto creará en él un nuevo tipo de moralidad —-moral-, de reciprocidad y no de obediencia" (Piaget, citado en Williams, 1972, p. 29).

- Fase abstracta: en esta el niño logra reflexionar sobre las normas, su origen, función y relatividad cultural, pero sobre todo, toma decisiones sobre racionalizaciones propias, no bajo modelos o presiones sociales, llena de contenido propio la noción de bien, con lo cual va más allá de la idea del deber ser.

Además de las etapas esbozadas es importante destacar que la noción de lo bueno sufre igualmente una transformación en el proceso moral del niño, inicialmente lo bueno está ligado a criterios emocionales: es bueno todo aquello que me gusta y me agrada, y no tiene en cuenta el establecimiento de las normas. El cierre del proceso de la construcción de la noción de bondad se da cuando el niño asume la regla de oro, fundamentada en la filosofía kantiana: tratar al otro como me gustaría que me trataran. 


\section{Acercamiento personal (reflexión)}

- Después de haber analizado la incidencia del aprendizaje por modelamiento y el proceso de formación del criterio moral, ¿cómo cree usted que incide el desarrollo moral en la formación de conductas prosociales (acciones socialmente correctas sin esperar nada a cambio) y en el desarrollo de competencias ciudadanas?

- Cuando los padres envían mensajes contradictorios, por ejemplo, le piden al niño hacer algo que ellos no hacen, ¿cómo afecta esto el juicio o reflexión moral del niño?

\section{Actividades sugeridas}

Búsquedas en Internet y bibliotecas

Búsquedas de casos en prensa
- Profundice en las obras de los autores citados en la conceptualización general sobre las etapas del desarrollo moral.

- Investigue sobre los periodos o edades que comprende cada una de estas etapas, según las propuestas de Kohlberg y Piaget, contrástelas con nuestra realidad y proponga los periodos acordes a nuestro contexto.

- Elabore un breve texto sobre la importancia que podría tener el juego grupal en la construcción de las normas sociales en los niños y adolescentes.

- Ilustre un caso de infracción de la ley por parte de un menor y la justificación de este. Evalúe a qué tipo de moralidad responden sus argumentos. 
Preguntas para debates grupales

- ¿Cuáles son los factores que en nuestro medio obstaculizan el paso de una moralidad heterónoma a una moralidad autónoma?

- En el caso del adolescente infractor, si alcanza a tener una comprensión autónoma de la moralidad, ¿qué lo empuja o motiva a transgredir la norma social?

\section{Bibliografía básica}

Kohlberg, L. (1976). Conducta y desarrollo moral. Nueva York: Holt, Rinehart and Winston.

Piaget, J. (1971). El juicio moral en el niño. Barcelona: Fontanela.

Williams, K. (1972). El desarrollo moral. Buenos Aires: Ateneo.

\section{Bibliografía complementaria}

Habermas, J. (1991). Erläuterunger zur Diskursethik. Fráncfort: Suhrkamp.

Habermas, J. (1999). La inclusión del otro: Estudios de teoría política. Barcelona: Paidós.

Higgins, A., Kohlberg, L. y Power, C. (1989). La educación moral. Barcelona: Gedisa.

Papalia, D. y Olds, S. (1999). Psicología del desarrollo. Ciudad de México: McGraw-Hill.

Piaget, J. (1973). La psicología del niño. Madrid: Morata.

Spranger, E. (1961). Formas de vida: Psicología y ética de la personalidad. Madrid: Revistas de Occidente.

Villegas, C. (1995). Acción moral: De una moralidad estratégica a una moralidad de principios o solidaridad. Revista Latinoamericana de Psicología, 27, 463-470. 
Tema 5. Desarrollo moral de los niños

Werner, H. (1972). The Concept of Development from a Comparative and Organismic Point of View. En C. Stendler-Lavatelli y F. Lavetelli (eds.), Readings in Child Development and Behavior (pp. 47-54). Nueva York: Harcourt Brace Jovanovich. 


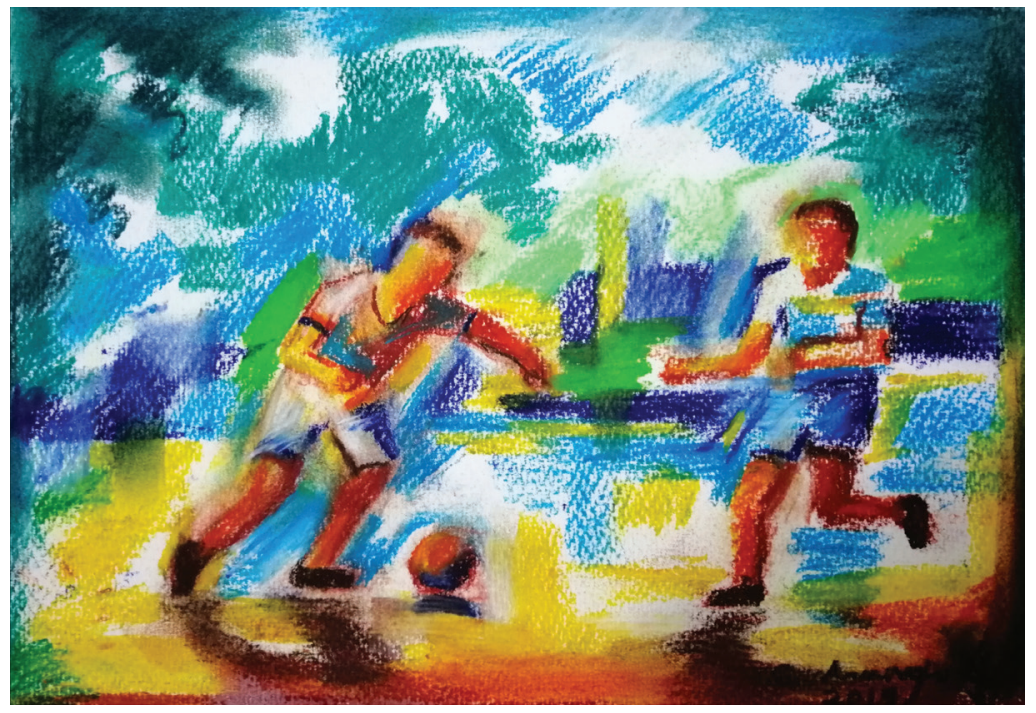

Veo que los niños juegan y luego salen peleando, también al rato vuelven otra vez a jugar y después se reconcilian, jugando aprenden a estar con los otros.

Madre de familia Hogar Infantil Fundehi, barrio El Arroyo, Cazucá, Soacha, 2017 